\title{
MODOS DE ENFRENTAMENTO DO HIVIAIDS: DIREITOS HUMANOS, VULNERABILIDADES E ASSISTÊNCIA À SAÚDE
}

\author{
Modes of Coping HIVIAIDS: Human Rights, Vulnerability and Health Care
}

Modos de Enfrentamiento del VIH/sida: Derechos Humanos, Vulnerabilidades y Asistencia de Salud

\author{
Érica Catarine Ataíde Maia \\ Leandro Passarinho Reis Junior \\ Universidade Federal do Pará
}

\begin{abstract}
RESUMO
O enfrentamento do HIV/Aids configura-se como um desafio para sociedade contemporânea, tendo em vista os diversos aspectos envolvidos nesta epidemia. Este estudo visa, analisar, por meio de estudos teóricos, os enfrentamentos sociais do HIV/Aids, circunscritos nos referenciais de direitos humanos, vulnerabilidade e assistência à saúde no Brasil. Verificou-se que a noção de direitos humanos trouxe contribuições inovadoras, demonstrando que sua violação aumenta a possibilidade de disseminação do HIV; o conceito de vulnerabilidade propõe uma análise das estruturas que incorporem a interdependência de aspectos individuais, sociais e programáticos na maior ou menor exposição ao contágio pelo HIV; a assistência à saúde no contexto de HIV/Aids perpassa a esfera da assistência integral na saúde pública no país. Finalmente, acentua-se que a reflexão destes aportes teóricos em interface com o enfrentamento do HIV/Aids demonstra que as desigualdades, discriminações, precariedades do sistema de saúde possuem uma estreita relação com a dinâmica de saúde-adoecimento.
\end{abstract}

Palavras-chave: HIVIAids; Direitos Humanos; Vulnerabilidade; Saúde.

\begin{abstract}
Coping with HIVIAIDS configures itself as a challenge for contemporary society, in view of the control several aspects of the epidemic. In this research, the objective was to analyze, through theoretical studies, the HIVIAIDS social coping, circumscribed in the references of human rights, vulnerability and health care in Brazil. It was found that the notion of human rights brought innovative contributions, demonstrating that their violation increases the possibility of dissemination of HIV; the concept of vulnerability is an analysis of structures that incorporates an interdependence of individual, social and programmatic aspects in greater or lesser exposure to HIV infection; health care in the context of HIVIAIDS permeates integral public health care in the country. Finally, a reflection on these theoretical contributions in interface with HIVIAIDS coping,
\end{abstract}


demonstrate them inequalities, discriminations, health system precariousness are closely related to the health-disease dynamics.

Keywords: HIVIAIDS; Human Rights; Vulnerability; Health.

\section{RESUMEN}

El enfrentamiento del VIH/SIDA se constituye como desafío para la sociedad contemporánea, teniendo en cuenta los diversos aspectos implicados en esta epidemia. En ese ensayo, el objetivo fue analizar a través de estudios teóricos, los enfrentamientos sociales del $\mathrm{VIH} / \mathrm{sida}$, basadas en los referenciales de derechos humanos, vulnerabilidad y asistencia a la salud en Brasil. Se constató que la noción de derechos humanos ha aportado contribuciones innovadoras, demostrando que su violación aumenta la posibilidad de diseminación del VIH; el concepto de vulnerabilidad propone una revisión de las estructuras que incorporen la interdependencia de aspectos individuales, sociales y programáticos en la mayor o menor exposición al contagio por el $\mathrm{VIH}$; la asistencia a la salud en el contexto del $\mathrm{VIH} /$ sida atravesa la esfera de la asistencia integral en la salud pública en el país. Finalmente, se acentúa la reflexión de estos aportes teóricos en interfaz con el enfrentamiento del $\mathrm{VIH} / \mathrm{sida}$ demostrando que las desigualdades, discriminaciones, precariedad del sistema de salud muestran relación estrecha con la dinámica de salud-enfermedad.

Palabras clave: VIH/sida; Derechos Humanos; Vulnerabilidad; Salud.

\section{INTRODUÇÃO}

A epidemia da aids ${ }^{1}$ surgiu em um período no qual as autoridades sanitárias mundiais presumiam que as doenças infecciosas se encontravam controladas, considerando as tecnologias e os avanços do saber médico moderno. A pandemia gerou comportamentos e reações coletivas que promoveram estratégias políticas oficiais em diversos contextos. $A$ complexidade e o dinamismo que caracterizaram o HIV/Aids ${ }^{2}$ traçam diversas mudanças epidemiológicas ao longo de mais de três décadas da doença, assim como a evolução das respostas sociais e políticas (Villarinho et al., 2013).

Segundo Garcia e Souza (2010), o cenário do HIVIAids no Brasil é marcado por nuances aderentes à realidade de desigualdade social do país. O processo de disseminação da epidemia e seu impacto na população são diferenciados, sendo assim, reconhecer e identificar a diversidade e especificidade desse processo é extremamente importante para o

\footnotetext{
${ }^{1} \mathrm{O}$ termo Aids, sigla originada do inglês, que significa Síndrome da Imunodeficiência Adquirida (Acquired Immunodeficiency Syndrome) será utilizado em caixa baixa, seguindo recomendação do Departamento Nacional de Doenças Sexualmente transmissíveis. Disponível em URL: http://www.aids.gov.br

2 HIV é uma sigla, com origem no inglês, que significa Vírus da Imunodeficiência Humana (Human Immunodeficiency Virus). Para fins de facilitação textual, os dois termos "HIV/Aids" serão utilizados juntamente, quando não prejudicarem a compreensão do seu significado, porém deixa-se claro que as siglas não são sinônimas.
}

Rev. Nufen: Phenom. Interd. | Belém, 11(1), 178-193, jan. - abr., 2019. 
planejamento e implementação de políticas e programas direcionados ao atendimento dos mais vulneráveis à exposição ao HIV/Aids.

O Brasil, levando em conta outros programas de controle de doenças, enfrentou e continua combatendo a aids de forma notável, na defesa contundente dos direitos humanos, com produção de campanhas preventivas, distribuição de antirretrovirais no sistema público de saúde, com a implantação de laboratórios e serviços especializados para assistência das Pessoas Vivendo com HIV/Aids (PVHA) e com financiamento para pesquisas científicas (Greco, 2016).

O HIV/Aids passou por diversos momentos em sua história no contexto brasileiro, momentos estes que atravessam a própria situação política do país. A primeira fase da doença, datada do início da década de 1980, com o surgimento dos primeiros casos de aids no Brasil, caracterizou-se pelo descaso das autoridades governamentais, acompanhada de um período de medo, estigma e discriminação. Na ausência de uma direção política nacional, as respostas à epidemia acabaram surgindo nas comunidades mais afetadas e em setores progressistas, o que levou a formação das primeiras organizações não governamentais (Villarinho et al., 2013).

A segunda fase é marcada pela resposta política à epidemia no Brasil, estendendo-se aproximadamente de 1986 até 1990, quando a liderança do Programa Nacional de DST/Aids (PNDST/AIDS) se estabeleceu, seguindo as mudanças políticas do país. A terceira fase corresponde ao período de 1990 a 1992, marcada pela falta de diálogo entre a sociedade civil e o governo federal, em que se pode visualizar a dificuldade de sustentar uma resposta de enfrentamento em longo prazo à epidemia. Por fim, a quarta fase concerne ao ano de 1993 até os dias atuais, apresentando uma reorganização do PNDST/AIDS no Ministério da Saúde e uma efetivação da política de controle da epidemia.

Neste sentido, Villarinho et al. (2013) apontam que, ao longo das últimas décadas da epidemia, o conjunto de intervenções direcionadas à qualidade da assistência de PVHA esteve constantemente no escopo das políticas públicas de saúde. O planejamento dessas políticas voltadas ao HIVIAids culminou na regulamentação de várias leis, programas e coordenações de saúde, assim como teve uma função preponderante na organização e efetividade dos Serviços de Assistência Especializada em HIV/Aids.

Deste modo, ratifica-se a importância das pesquisas e produção de conhecimento no processo de construção do campo discursivo no enfrentamento do HIVIAids:

Faz-se necessário destacar que os dados e pesquisas sobre discriminação, desigualdade, violência, exclusão e vulnerabilidade são hoje arenas de suma importância no campo da construção de ações governamentais bem como de 
políticas de ações afirmativas. A importância da produção de conhecimento e pesquisa se destacam na construção não somente de uma agenda política, mas igualmente no desenho das necessidades e características de certos sujeitos específicos (Moutinho, Aguião, \& Neves, 2018, p. 10).

Ao fazermos este traçado histórico que acompanha os estágios que a epidemia da aids atravessou, percebemos que vários dispositivos foram acionados diante do enfrentamento à doença. Abordando essa realidade, temos nos referenciais dos direitos humanos, do conceito da vulnerabilidade e da assistência à saúde, propostas de aproximação destes referenciais teóricos para a compreensão da temática e fomento ao debate em torno do enfrentamento social do HIVIAids.

Diante do exposto, o presente artigo tem como objetivo analisar, por meio de estudos teóricos, os enfrentamentos sociais da epidemia de HIV/Aids, circunscritos nos atravessamentos de referenciais dos direitos humanos, do conceito da vulnerabilidade e da assistência à saúde no Brasil.

\section{DIREITOS HUMANOS E HIVIAIDS}

Garantir a dignidade do ser humano é o que traz sentido para a discussão a respeito da função social da propriedade intelectual diante do direito à saúde, trata-se de uma luta constante contra as desigualdades sociais. Desta maneira, quando se analisa a problemática envolvendo o HIVIAids, não é possível dissociarmos direitos humanos do enfrentamento da epidemia. O processo de reconhecimento do direito ao acesso universal a prevenção, diagnóstico e tratamento é considerado uma questão relevante aos direitos humanos desde os primórdios da epidemia (Brasil, 2008).

A efetivação da promoção do acesso universal à PVHA enfrenta obstáculos como o estigma e a discriminação, acentuando ainda mais o impacto da doença. Este é um motivo que implica na impossibilidade de dissociar a resposta brasileira do processo dinâmico de construção e reconstrução de conceitos e discursos trazidos pelos vários movimentos sociais. Portanto, é de extrema importância o diálogo constante com o reconhecimento de identidades, especificidades e direitos, o que permite a construção de uma resposta que contemple as necessidades de uma população tão diversificada.

Uma importante contribuição em expor a imbricada relação entre direitos humanos e aids é demonstrar que a violação de direitos humanos possibilita um incremento à disseminação do HIV. Gruskin, Hendrinks e Tomasevski (1996) afirmam que existem três fases distintas nas quais a relação entre direitos humanos, prevenção e controle do HIV/Aids prosseguiu. 
Na primeira, logo no surgimento da doença, existiram propostas utilizadas como "medidas de saúde" - isolamento, testes obrigatórios e quarentena - que feriam absolutamente os direitos humanos. Na segunda fase, começando por volta de 1987, já se reconhecia que a discriminação contra a PVHA reduzia a eficácia dos esforços para prevenção e controle na saúde pública. A última fase, iniciada nos anos 90 , nos levou a uma nova perspectiva sobre a pandemia, esta nova concepção centrou-se na vulnerabilidade à infecção pelo HIV. Tornou-se claro que o desrespeito aos direitos à dignidade humana era um dos principais contribuintes para a problemática do HIV/Aids.

De acordo com Galvão (2000), a noção de direitos humanos trouxe contribuições inovadoras no que tange à epidemia de aids, por ampliar o entendimento sobre saúde. Nesta perspectiva, tal concepção nega que a aids seja somente um problema restrito ao campo da saúde, inserindo-a em um contexto mais amplo, no qual orientação sexual, pobreza e gênero se cruzavam de diferentes maneiras com a pandemia.

Conforme aponta Nascimento (2009), as políticas de apoio aos direitos humanos constituem uma das respostas às discriminações sofridas pela PVHA. A utilização da concepção dos direitos humanos é embasada nos princípios da Declaração Universal dos Direitos Humanos de 1948, em Convenções da qual o Brasil é signatário, na Constituição Federal Brasileira e na Declaração de Compromisso Sobre o HIV/Aids de 2001, conhecida como Declaração UNGASS. Sendo assim, o uso destes instrumentos da legislação, referentes ao respeito aos direitos dos cidadãos, sustenta a resposta jurídica às discriminações de PVHA.

A Declaração UNGASS culmina-se dos processos de conscientização, cujo compromisso é a mobilização na luta contra o HIV/Aids, sendo o Brasil um dos países signatários. Em 2006, foi realizada uma reunião de avaliação dos cumprimentos das metas da Declaração UNGASS. Nessa reunião foi elaborada a Declaração Política (UNGASS +5$)^{3}$, em que se destacam alguns itens mais diretamente relacionados aos direitos humanos:

Reafirmamos que a plena efetivação de todos os direitos humanos e das liberdades fundamentais para todas as pessoas é um elemento essencial na resposta global à pandemia do HIV/Aids, inclusive nos setores de prevenção, tratamento, assistência e apoio, e reconhecemos que chamar a atenção sobre o estigma e a discriminação é também um elemento crítico no combate à pandemia global do HIV/Aids;

\footnotetext{
${ }^{3}$ Fonte: <www.aids.gov.br/es/publicacao/2011/ungass-2006-declaracion-politica> Acesso em 03 de fevereiro de 2017.
} 
Reconhecemos também que, para construir uma resposta abrangente, é preciso: superar quaisquer barreiras legais, regulatórias e comerciais, entre outras, que bloqueiam o acesso à prevenção, tratamento, assistência e apoio; captar recursos adequados; promover e defender os direitos humanos e as liberdades fundamentais para todas as pessoas; promover a igualdade de gêneros e o empoderamento das mulheres; promover e proteger os direitos das meninas, no sentido de reduzir sua vulnerabilidade ao HIV/Aids; aperfeiçoar os sistemas de saúde e apoiar os trabalhadores da saúde; incentivar um maior envolvimento das pessoas vivendo com o HIV; ampliar o uso de mecanismos de prevenção reconhecidamente efetivos e abrangentes; fazer todo o necessário para assegurar o acesso aos medicamentos vitais e aos mecanismos de prevenção; desenvolver, no menor prazo possível, ferramentas melhores - medicamentos, diagnósticos e tecnologias de prevenção, incluindo vacinas e microbicidas - para o futuro;

Comprometemo-nos a intensificar esforços para aprovar, fortalecer ou enfatizar, segundo apropriado, legislações, regulamentações e outras medidas, a fim de eliminar todas as formas de discriminação e assegurar o pleno usufruto de todos os direitos humanos e liberdades fundamentais pelas pessoas vivendo com o HIV e membros de grupos vulneráveis, e em particular para assegurar seu acesso, entre outros, a educação, herança, emprego, assistência médica, serviços sociais e de saúde, prevenção, apoio e tratamento, informação e proteção legal, respeitando-Ihes a privacidade e a confidencialidade, e a desenvolver estratégias para combater o estigma e a exclusão social ligados à epidemia.

Embora existam diferentes abordagens para o enfrentamento da epidemia, dos mais diversos grupos - ativistas políticos, profissionais da área da saúde, ONGs Aids, movimentos sociais -, os princípios, diretrizes, prioridades de ação e todos os atores que, de maneira direta ou indireta, engajaram-se na luta contra a aids, possuem o desejo comum da garantia dos direitos sociais dos cidadãos frente ao HIV/Aids. Neste sentido, o movimento de luta contra a aids atua com o propósito de transformações éticas, norteadas por valores como dignidade, igualdade, respeito à diferença, tendo como principal estratégia os vínculos de solidariedade, resgate da alteridade, mobilização social e participação cívica (Brasil, 2008).

No tocante à discussão sobre os direitos humanos e o enfrentamento do HIV/Aids, percebe-se que as desigualdades e as precariedades sociais vivenciadas no 
Brasil têm direta relação com os problemas de saúde, incluindo-se a epidemia da aids. Com a ocorrência da doença no mundo, a sociedade brasileira foi obrigada a olhar para questões que insistentemente recusava-se a ver: a desigualdade, o preconceito, a hipocrisia, a falência do sistema de saúde, a incoerência da justiça, a fragilidade das relações pessoais etc. Neste sentido:

Com a aids, percebemos que a desigualdade, o preconceito, a discriminação, o racismo também são doenças graves, que acometem grande parcela da sociedade brasileira. Entendemos que garantir, assegurar e promover saúde significa combater tanto os males causados por vírus, bactérias e afins como aqueles provenientes de valores morais conservadores, segregacionistas e reacionários. Aprendemos que saúde e dignidade são as duas faces de uma mesma realidade. E que lutar por saúde é antes de tudo lutar pela dignidade humana, no sentido mais amplo e irrestrito que esse termo pode possuir (Brasil, 2008, p. 17).

No Brasil e no mundo, o impacto do preconceito na disseminação do vírus impeliu uma articulação entre direitos humanos e aids, produzindo um discurso de maior respeito aos direitos humanos como dispositivo essencial para o combate à epidemia. $E$ isso denota que lutar contra a aids implica combater as formas de desigualdade, preconceito e discriminação. No campo da saúde pública, significa articular a noção de saúde com outras dimensões da vida social.

As autoras Ferraz e Paiva (2015) apontam que recentes ensaios clínicos direcionados para a implantação de novas tecnologias de prevenção ao HIV/Aids como a circuncisão, a profilaxia pré-exposição e a supressão da carga viral pelo tratamento com antirretrovirais - acarretam transformações, ainda de retorno incerto e ambivalente, para a epidemia de aids. Com estas mudanças, são importantes a participação e a ênfase nos direitos humanos para reestruturar os princípios que regeram o enfrentamento da aids no Brasil e que demonstram ser centrais para a efetividade dos programas de prevenção.

Neste sentido, dois movimentos são primordiais: fortalecer os meios de participação da sociedade como condição fundamental para que as estratégias de prevenção sejam legitimadas e responsivas às necessidades da população, bem como recuperar o diálogo sobre sexualidade, não apenas com informações técnicas, mas também promovendo o respeito à diversidade e enfrentando a estigmatização, que contribui para a maior vulnerabilidade dos grupos mais afetados pelo HIVIAids.

\section{VULNERABILIDADES AO HIVIAIDS NO CONTEXTO BRASILEIRO}

Rev. Nufen: Phenom. Interd. | Belém, 11(1), 178-193, jan. - abr., 2019. 
A origem do conceito de vulnerabilidade nasce na área da advocacia internacional pelos Direitos Universais do Homem, designando os grupos ou indivíduos desamparados, tanto no âmbito jurídico, quanto político e social, na sua proteção, promoção e garantia de cidadania. Este termo tem sido utilizado nos últimos anos por pesquisadores e profissionais do campo da saúde, incorporando este conceito às discussões de ações e políticas relacionadas à epidemia de HIVIAids (Ayres, França Júnior, Calazans, \& Saletti Filho, 2003; Lebrego, 2008; Schaurich \& Freitas, 2010).

De acordo com Schaurich e Freitas (2010), o conceito de vulnerabilidade surge para dar conta das lacunas e equívocos deixados pelas concepções de "grupo de risco" e "comportamento de risco", amplamente divulgados e associados ao período inicial da infecção pelo HIV. A insuficiência destas concepções em possibilitar compreensões relacionadas aos rumos da epidemia, em propiciar explicações para além daquelas do tipo causa-efeito e restringir as ações e as políticas públicas trazendo - com isso, respostas ineficazes frente ao avanço epidêmico - foi uma infeliz realidade no contexto inicial da aids.

O conceito de vulnerabilidade associado à infecção pelo HIV e ao adoecimento por aids foi formulado por Jonathan Mann, primeiro coordenador da Coalização Global de Políticas Contra Aids. Mann pesquisou o tema da vulnerabilidade global à aids, através de uma metodologia que propõe analisar as estruturas que incorporem a interdependência do comportamento individual, do âmbito coletivo e do social (Ayres et al., 2003).

Mann, Tarantola e Netter (1993) afirmam que, ao analisar a vulnerabilidade, é importante considerar a comunidade, além de fatores nacionais e internacionais, que possam influenciar na vulnerabilidade pessoal durante o curso de uma vida. Na tentativa de ampliar o conceito de vulnerabilidade ao contexto brasileiro, Ayres et al. (2003) indica que a compreensão sobre o tema englobe o contexto social - o que pode acarretar maior vulnerabilidade ao HIV e ao adoecimento pela aids - e, de modo indissociável, a maior ou menor disposição de recursos para a proteção das pessoas contra enfermidades. Este conceito de vulnerabilidade é apresentado pelo autor em três perspectivas interrelacionadas:

- Vulnerabilidade Individual: remete ao grau e à qualidade da informação que cada indivíduo dispõe sobre o HIV/Aids, sua capacidade de elaboração das informações e aplicação das mesmas em suas vivências, e as possibilidades efetivas de transformar essas preocupações em práticas protegidas e protetoras.

- Vulnerabilidade Social: refere-se a um conjunto de fatores sociais que determinam o acesso a informações, as possibilidades de assimilação e o poder de incorporá-las a mudanças práticas; estes aspectos não dependem somente do indivíduo, mas de outras estruturas, como acesso a meios de comunicação, 
educação, recursos materiais, bens culturais, as restrições ao exercício da cidadania, exposição à violência, decisão política ou de investimentos dados à saúde e condições de moradia e trabalho.

- Vulnerabilidade Programática: diz respeito aos recursos sociais necessários ao combate do HIV/Aids, às práticas do poder público no sentido de fortalecer os indivíduos diante da epidemia, com ações preventivas e educacionais, assim como se refere ao grau e à qualidade de compromisso das instituições, dos financiamentos, da gerência e do monitoramento dos programas nos diferentes níveis de atenção.

Paris (1999) salienta que o modelo conceitual proposto por Mann, Tarantola e Netter (1993) mostra-se impregnado da tradição norte-americana de pesquisa social, ao focalizar o âmbito individual segundo aspectos comportamentais e cognitivos. Dentro de uma visão crítica à obra de Mann, Paris apresenta um estudo sobre vulnerabilidade à aids em uma perspectiva que abrange aspectos psicossociais, a partir da população, decodificando o conceito de vulnerabilidade em três aspectos: o primeiro relacionado aos fatores estruturais da sociedade (desigualdade de renda, educação e acesso a serviços); o segundo referente aos aspectos fisiológicos e decorrentes das relações de gênero na sociedade; por fim, a vulnerabilidade na esfera da significação (conceito de risco, e a forma como se expressa, no imaginário social, além de seus diferentes significados através da história)

Discutir a relação dos indivíduos com a aids implica falar da situação social, política e cultural, de status econômico, de valores morais, de projeto de vida, situação legal e jurídica do país em que vive este indivíduo, condições de acesso aos serviços de saúde, e muitos outros fatores, ou seja, a tentativa de compreender qual o nível de vulnerabilidade de indivíduos, população e país à epidemia perpassa por diversos aspectos sociais. Se a aids progride atualmente com potencial incidência entre mulheres, jovens, pobres e negros, em geral, isso nos fala de uma vulnerabilidade histórica desses grupos, que se manifesta na sua falta de poder político e autonomia para reivindicar e manter direitos.

Como ilustrativo do cenário das vulnerabilidades ao HIV/Aids atingirem grupos de maneira desigual, aborda-se a questões da feminização da aids como elucidativo da discussão sobre grupos vulneráveis à epidemia. Sobre os dados demonstrados no Boletim Epidemiológico de IST/HIV (Brasil, 2018), quanto à forma que a epidemia se apresenta no gênero feminino, constata-se que: $96,6 \%$ das mulheres com diagnóstico de HIV são heterossexuais; com faixa etária em maior detecção entre 25 a 34 anos; mulheres possuem menor escolaridade que homens, apenas $4,3 \%$ das mulheres possuem curso superior, dos 
homens $14,1 \%$ com nível superior; mulheres negras representam $63,3 \%$ dos óbitos notificados por raça/cor no ano de 2017.

Conforme Lebrego (2008), os fatores políticos e econômicos que impulsionaram a epidemia de HIV/Aids estão também diretamente ligados à organização social das estruturas de gênero e sexualidade, cujas hierarquias fazem das mulheres - principalmente as de baixa renda - extremamente vulneráveis à infecção pelo HIV, isto é, a feminização da aids representa o aumento do número de mulheres infectadas pelo HIV/Aids em decorrência das vulnerabilidades sociais as quais elas estão expostas.

A vulnerabilidade das mulheres à infecção está estreitamente ligada ao machismo e a uma cultura patriarcal. O processo histórico de subjugo das mulheres aos homens, em várias esferas sociais, bem como as opressões por elas vivenciadas propiciaram uma série de situações de vulnerabilidades das mulheres ao HIV, como: relações sexuais desprotegidas por falta de poder de negociação do preservativo, responsabilização unilateral dos meios de contracepção, dependência econômica e emocional do parceiro, usar ou ter parceiro usuário de drogas injetáveis, comercialização do sexo e violência sexual, são alguns fatores que facilitam a exposição das mulheres ao HIV (Lebrego, 2008; Ceccon \& Meneguel, 2017).

Sobre as questões de vulnerabilidades das mulheres ao HIV/Aids, as autoras Lima e Schriber (2013) assinalam:

Isso implica em uma aproximação da vulnerabilidade das mulheres às DST/HIV como desigualdade de poder de sujeito social, a que vêm se somar outras desigualdades, como as sócio-econômicas, as étnico-raciais ou as conexas ao acesso às instituições de saúde, denominada de vulnerabilidade programática. (Lima \& Schriber, 2013, p. 950).

O recorte da feminização da aids no panorama da pandemia ressalta a maneira disfórmica que o HIVIAids atinge a sociedade. Se, por um lado, todos estão expostos ao risco de infecção à doença, por outro, as condições que alguns grupos dispõem para se proteger determina sua vulnerabilidade, ou seja, quanto maior seu amparo social e a assistência à saúde, menor será sua vulnerabilidade. A vulnerabilidade é determinada por acesso à informação, reconhecimento da suscetibilidade, eficácia das formas de prevenção, pelo acesso a recursos e capacidade de adotar métodos de prevenção.

\section{ASSISTÊNCIA À SAÚDE DE PESSOAS VIVENDO COM HIVIAIDS}

A saúde coletiva e as políticas públicas no Brasil têm um grande desafio social e político no que tange aos processos endêmicos constituídos no país, sobretudo, aqueles 
que atingem a população em condições sociais e econômicas mais desfavoráveis. No âmbito nacional, assim como no internacional, a epidemia de HIV/Aids permanece se disseminando e a efetividade de sua prevenção e controle, mesmo após mais de três décadas de combate à doença, ainda continua sendo um desafio global (Santos, Cruz, Decotelli, Chrispim, Abreu, 2011).

Apesar das reconhecidas estratégias brasileiras para prevenção, controle e tratamento do HIV/Aids, a epidemia ainda se apresenta como um problema grave de saúde no Brasil com diferentes aspectos, composta por várias subepidemias, não existindo um padrão epidemiológico em todo o país, mas sim um conglomerado de subepidemias regionais que podem ter relação com as grandes desigualdades socioeconômicas do país (Brasil, 1999; Santos et al., 2011).

Logo, compreender de que forma os serviços de assistência à saúde das PVHA estão sendo efetivados e ampliados nos diversos níveis de atenção é imprescindível ao enfrentamento do HIV/Aids. Uma vez que é um direito fundamental de toda PVHA ter acesso à assistência e ao tratamento, oferecidos sem restrições pela rede de saúde pública, garantindo sua melhor qualidade de vida (Brasil, 1999). Neste contexto, destaca-se o excerto abaixo retirado do documento de Política Nacional de HIV/Aids:

Promover a saúde é parte integrante e substantiva de todo o processo de desenvolvimento econômico e social com equidade, e isso representa um desafio para todos aqueles que hoje se encontram na frente de luta contra a aids (Brasil, 1999, p. 14).

No que concerne à saúde pública, toda a assistência aos usuários soropositivos é disponibilizada pelo Sistema Único de Saúde (SUS), que é um sistema integrado e articulado de serviços e ações de promoção, prevenção, tratamento e assistência à saúde, sob a incumbência das esferas do governo federal, estadual e municipal, e ainda, dos serviços privados, atuando de forma complementar a prestação de serviços aos usuários (Frutoso \& Saur, 2011).

A partir das diversas mudanças nas políticas públicas de saúde ocorridas no Brasil após a criação dos SUS, Greco (2016) afirma que é pouco provável que a resposta brasileira à epidemia da aids teria avançado o que avançou sem o SUS, tornando-se realmente um grande marco de mudança na saúde publica brasileira.

Quanto às transformações implementadas no contexto de HIV/aids, Greco (2016) analisa que, a partir de 1991, o Brasil iniciou a distribuição do AZT pelo SUS, fabricado no país a partir de 1993. O acesso aos medicamentos confirmava a política dos direitos sociais e humanos explicitados na Constituição de 1988 e nos preceitos do SUS. E, 
no ano de 1996, pressionado pelos movimentos sociais e apoiado pela academia, o governo brasileiro sancionou uma lei dispondo sobre a obrigação do Estado de distribuir, de forma universal e gratuita, os medicamentos para o tratamento das PVHA, adotando a política do direito ao acesso aos medicamentos antirretrovirais no SUS.

Levando em conta essa realidade, no cenário que a aids se apresenta em nosso país, é imprescindível refletirmos sobre como estão sendo sistematizadas e implementadas as políticas públicas nesse contexto, as práticas de saúde e a forma de participação dos atores envolvidos - usuários, profissionais de saúde, gestores e a população geral. A respeito do enfrentamento do HIV/Aids na saúde pública, o Documento Nacional de DST/Aids (1999) pontua que:

Esses novos contornos colocam-nos o desafio da implementação do SUS, buscando-se a integração de suas ações, a articulação intersetorial, a sustentabilidade das ações e programas, o fortalecimento dos espaços institucionais e a construção de uma política nacional de DST/aids [...] para conseguirmos responder às necessidades vividas e manifestadas pelo conjunto da sociedade, priorizando os setores mais afetados pela epidemia. (Brasil, 1999, p. 10)

Considerando a importância epidemiológica, a magnitude social, a infecção e morbidade por HIVIAids, o aprimoramento da organização da rede de atenção integral e universal às pessoas vivendo com síndrome no país, foram criados serviços especializados. Como um dos principais estabelecimentos de assistência em HIVIAids existe o Centro de Testagem e Aconselhamento (CTA) e o Serviço de Atenção Especializada (SAE). O CTA realiza ações de testagem e prevenção de DST/HIV/Aids, destinadas, prioritariamente, a segmentos populacionais considerados em situação de maior vulnerabilidade e à população em geral, presta serviço de acolhimento e o aconselhamento, pré e pós testagem. O SAE oferece serviço ambulatorial direcionado à atenção integral às pessoas com DST/HIV/Aids, conta com uma equipe multidisciplinar, com a utilização de protocolos clínicos e terapêuticos; propiciando o vínculo com uma equipe ao longo do tratamento (Brasil, 2010).

Greco (2016) ressalta que há diversos desafios para a sustentabilidade do programa brasileiro de combate ao HIV/aids no sistema público de saúde. Primeiramente, o enfrentamento das desigualdades sociais, da pobreza e da discriminação, por aumentarem a vulnerabilidade das pessoas em relação ao HIV/aids e dificultarem o acesso à necessária prevenção, aos cuidados médicos e à adesão ao tratamento. Outro ponto é o acrescente número de PVHA iniciando tratamento, além da necessidade de novos medicamentos para os que já falharam nos esquemas iniciais da ARV, visto que, devido à expansão do 
diagnóstico e da esperada necessidade de novos esquemas de medicamentos que elevam os custos do tratamento, os investimentos necessários continuarão a subir.

Conforme Oliveira, Landroni, Silva e Ayres (2005), quando se examina a questão da humanização e integralidade no campo específico de atenção à saúde de PVHA, verificase que os profissionais consideram suas práticas adequadas, por haver escuta e retorno às diferentes necessidades dos usuários. No entanto, tais necessidades não estão sendo incorporadas ao projeto político de atenção à saúde no âmbito do HIV/aids. As precárias condições sociais e econômicas dos usuários do serviço público de saúde tornam inevitáveis e frequentes as situações em que os profissionais precisam suprir carências dos usuários - despesas ou rearranjos nas rotinas do serviço. Nessas situações os profissionais relatam sentimentos de impotência ou completa responsabilização perante essa realidade problemática.

De acordo com Moreira, Bachinni, Francês e Silva (2014), o profissional de saúde que atua com PVHA deve estar familiarizado com os desdobramentos de sua prática, seja em unidades básicas de saúde, centros de testagem, unidades de referência, clínica ambulatorial ou em hospital geral. Nos mais distintos contextos nos quais o crescimento da epidemia do HIV/Aids tem demandado a maior inserção dos assistentes sociais, enfermeiros, médicos, psicólogos e entre tantos outros, no serviço de assistência a estes pacientes, é relevante a contribuição destes profissionais para o desenvolvimento dos saberes sobre o HIV/Aids, problematizando questões relativas às dificuldades programáticas, coletivas e de assistência clínica.

Tais discussões perpassam a esfera da assistência integral e humanizada, bem como a saúde de PVHA, além disso, dispõem sobre o enfrentamento da saúde pública no contexto de prevenção, tratamento e acompanhamento de pessoas que vivem na condição de sorologia positiva. Deve ser priorizado o enfrentamento eficaz no âmbito da assistência à saúde no contexto do HIV/Aids, garantindo-lhes seus direitos, acesso e assistência, tendo em vista a diminuição das vulnerabilidades e proteção preconizada pelos direitos humanos nos mais diversos aspectos de suas vidas.

\section{CONSIDERAÇÕES FINAIS}

Este artigo apresentou formulações de referenciais teóricos no campo dos direitos humanos, vulnerabilidade e assistência à saúde direcionados ao enfrentamento da epidemia do HIVIAids. As imprescindíveis contribuições destes referenciais no que tange a seus atravessamentos nas dificuldades e avanços desenvolvidos no contexto de HIV/Aids são significativas para o aprimoramento do combate ao seu crescimento, diminuição de seus flagelos, desenvolvimento de novas tecnologias mais eficientes, assistência à saúde com integralidade e humanização a PVHA, contestação de políticas pouco eficazes, garantia 
de direitos e combate a práticas que ferem a dignidade humana, auxílio no planejamento de programas e projetos que visam ao enfrentamento do HIV/Aids.

Se, por um lado, a aids ainda é uma síndrome que causa sérias complicações à saúde e pode levar a morte, por outro, direcionar seu tratamento e prevenção somente às áreas médicas e às instituições de saúde já se provou não ser uma solução eficaz, pois o HIV/Aids é uma doença que necessita de propostas de enfrentamento transversais, dando conta de todo aspecto social envolvido no campo da saúde, educação, ciência, economia, política e relações sociais.

No tocante à discussão dos aportes de direitos humanos, quanto ao conceito de vulnerabilidade e assistência à saúde em interface com o enfrentamento do HIVIAids, demonstra-se que, em especial nos contextos do HIVIAids, as desigualdades, precariedades, discriminações, questões de sexualidade, dilemas da justiça, desestrutura do sistema de saúde e debilidade das relações pessoais, possuem relação estreita com a dinâmica de saúde-adoecimento.

Com ocorrência do HIVIAids no mundo, intimamente nos referimos à sociedade brasileira, percebemos que saúde e dignidade são expressões de uma mesma realidade, e lutar por saúde é antes de tudo combater desigualdades, preconceitos e lutar pela dignidade humana no sentido mais integral que este termo pode ser demonstrado em nossa vida prática.

\section{REFERÊNCIAS}

Ayres, J. R. C. M., França Júnior, I., Calazans, G. J., \& Saletti Filho, H. C. (2003). O conceito de vulnerabilidade e as práticas de saúde: novas perspectivas e desafios. In: Czeresnia, D., \& Freitas, C. M. (Org.). Promoção da saúde: conceitos, reflexões, tendências. (pp. 117-139). Rio de Janeiro: FIOCRUZ.

Brasil. (1999). Ministério da Saúde. Secretaria de Atenção à Saúde. Política Nacional de DST/Aids: princípios e diretrizes. Brasília, DF: o autor.

Brasil. (2008). Ministério da Saúde. Secretaria de Vigilância em Saúde. Direitos humanos e HIV/Aids: avanços e perspectivas para o enfrentamento da epidemia no Brasil. Brasília, DF: o autor.

Brasil. (2018). Ministério da Saúde. Secretaria de Vigilância em Saúde. Boletim Epidemiológico HIV Aids. Brasília, DF: o autor.

Ceccon, R. F., \& Meneguel S. N. (2017). Iniquidades de gênero: mulheres com HIV/Aids em situação de violência. Physis: Revista de Saúde Coletiva, 27(4), 1087-1103.

Ferraz, D., \& Paiva, D. (2015). Sexo, direitos humanos e AIDS: uma análise das novas tecnologias de prevenção do HIV no contexto brasileiro. Revista Brasileira de Epidemiologia, 19(1), 89-103. 
Frutuoso, J. T., \& Saur, B. ( 2011). O sistema único de saúde brasileiro e a clínica ampliada. In: Zurba, M. C. (Org.). Psicologia e Saúde Coletiva. (pp. 41-50). Florianópolis: Tribo da Ilha.

Galvão, J. (2000). AIDS no Brasil: a agenda de construção de uma epidemia. São Paulo: Editora 34.

Garcia, S. \& Souza, F. M. (2010). Vulnerabilidades ao HIV/aids no Contexto Brasileiro: iniquidades de gênero, raça e geração. Saúde Sociedade, 19(2), 9-20.

Greco, D. B. (2016). Trinta anos de enfrentamento à epidemia da Aids no Brasil, 1985-2015. Ciência \& Saúde Coletiva, 21(5), 1553-1564.

Gruskin, S., Hendrinks, A., \& Tomasevski, K. (1996). Human rights and responses to HIVIAIDS. In: Mann, J., \& Tarantola, D. J. M. (Org.). AIDS in the world II: the Global AIDS Policy Coalition. (pp. 326-340). London: Oxford University Press.

Lebrego, A. M. (2008). Estudo psicanalítico sobre a feminização da epidemia do HIV/Aids com usuários do Hospital Universitário João de Barros Barreto. (Dissertação de Mestrado). Universidade Federal do Pará, Belém.

Lima, M., \& Schriber, L. (2013). Violência e outras vulnerabilidades de gênero em mulheres vivendo com HIV/Aids. Temas em Psicologia, 21(3), 947-960.

Mann, J. M., Tarantola, D. J. M., \& Netter, T. W. (1993). A aids no mundo. Rio de Janeiro: Relume-Dumará.

Moreira, A. C., Bachinni, A. M., Francês, I., \& Silva, R. D. (2014). Cuidado no diagnóstico de HIV/aids: a escuta psicanalítica como dispositivo clínico no hospital geral. In: Moreira, A. C.; Oliveira, P. T. R., \& Piani, P. P. F. (Org.). Cuidado e Saúde: práticas e sentidos em construção. (pp. 45-72). Belém: Paka-Tatu.

Moutinho, L., Aguião S., \& Neves, P. S. C. (2018). A construção política das interfaces entre (homos)sexualidade, raça e aids nos programas nacionais de direitos humanos. Ponto Urbe [Online], 23, 01-21. Recuperado em 29 de dezembro 2018, de http://journals.openedition.org/pontourbe/5534.

Nascimento, V. L. V. (2009). Aids e Direitos Humanos: práticas sociais em situações de discriminação. Curitiba: Juruá Editora.

Oliveira, L. A., Landroni, M. A. S., Silva, N. E. K., \& Ayres, J. R. C. M. (2005). Humanização e cuidado: a experiência da equipe de um serviço de DST/Aids no município de São Paulo. Ciência \& Saúde Coletiva, 10(3), 689-698.

Paris, S. M. J. (1999). Aspectos psicossociais e a vulnerabilidade feminina. Folha Médica UNIFESP, 18(1), 41-50,

Santos, E. M., Cruz, M. M., Decotelli, P. V., Chrispim, P. P. M., \& Abreu, D. M. F. (2011). Avaliadores in situ (ação): reflexões e desafios sobre a institucionalização da prática avaliativa no PN DST/Aids. In: Campos, R. O., \& Furtado, J. P. (Org.). Desafios da avaliação de programas e serviços em saúde: novas tendências e questões emergentes. (pp. 205-221). Campinas: Editora da Unicamp.

Schaurich, D., \& Freitas, H. M. B. (2011). O referencial de vulnerabilidade ao HIVIAIDS aplicado às famílias: um exercício reflexivo. Rev. Esc. Enferm., 45(4), 989-995. 
Villarinho, M. V., Padilha, M. I., Berardinelli, L. M. M., Borenstein, M. S., Meirelles, B. H. S., \& Andrade, S. R. (2013). Políticas públicas de saúde face à epidemia da AIDS e a assistência às pessoas com a doença. Brasília: Revista Brasileira de Enfermagem, 66(2), 271-277.

\section{NOTAS SOBRE OS(AS) AUTORES(AS):}

Érica Catarine Ataide Maia - Mestre em Psicologia Social e Clínica. Psicóloga clínica e hospitalar. E-mail: ericacatarine.15@gmail.com

Leandro Passarinho Reis Junior - Doutor em Educação, Psicólogo e Professor Permanente do Programa de Pós-Graduação em Psicologia da UFPA. E-mail: Ipassarinho28@gmail.com

Recebido em: 24/07/2018. Aprovado em: 19/02/2019. 